Check for updates

London

Cite this as: $B M J$ 2021;372:n699 http://dx.doi.org/10.1136/bmj.n699 Published: 11 March 2021

\section{Covid-19: European countries suspend use of Oxford-AstraZeneca vaccine after reports of blood clots}

\author{
Jacqui Wise
}

Denmark has temporarily suspended use of the Oxford-AstraZeneca covid-19 vaccine as a precautionary move after reports of blood clots and one death. However, the European Medicines Agency (EMA) and the UK's regulatory body have said that there is no indication that vaccination is linked to thromboembolic events.

Eight other countries-Norway, Iceland, Austria, Estonia, Lithuania, Luxembourg, Italy, and Latvia-have also suspended use of AstraZeneca's vaccine. The decisions are a further setback for Europe's vaccination campaign, which has struggled to pick up speed, partly because of delays in delivering the AstraZeneca vaccine.

The Danish Health Authority said that one person in Denmark had died after receiving the AstraZeneca vaccine and that it would suspend the drug's use for two weeks while the case was investigated. "It is important to point out that we have not terminated the use of the AstraZeneca vaccine-we are just pausing its use," said the Danish Health Authority's director, Soren Brostrøm.

On 10 March the EMA said that Austria had suspended the use of a batch of AstraZeneca vaccines after one person had multiple thrombosis diagnosed and died 10 days after vaccination. Another person was admitted to hospital with pulmonary embolism after being vaccinated and is now recovering. The EMA said that two other reports of thromboembolic event cases had also been received from that batch, which was delivered to 17 EU countries and comprised a million doses.

\section{Close review}

The EMA's safety committee is reviewing the issue but said that there was currently no indication that vaccination has caused these conditions, which are not listed as side effects. It said that the information available so far showed that the number of thromboembolic events in vaccinated people was no higher than that seen in the general population. It said that, as of 10 March, 30 cases of thromboembolic events had been reported among the five million people given the AstraZeneca vaccine in the European Economic Area.

Phil Bryan, vaccines safety lead for the UK's Medicines and Healthcare Products Regulatory Agency, said, "More than 11 million doses of the AstraZeneca vaccine have now been administered across the UK. Reports of blood clots received so far are not greater than the number that would have occurred naturally in the vaccinated population." He added that the agency was keeping the issue under close review but that available evidence did not confirm that the vaccine was the cause.
A spokesperson for AstraZeneca said, "Patient safety is the highest priority for AstraZeneca. Regulators have clear and stringent efficacy and safety standards for the approval of any new medicine, and that includes Covid-19 Vaccine AstraZeneca.

“An analysis of our safety data of more than 10 million records has shown no evidence of an increased risk of pulmonary embolism or deep vein thrombosis in any defined age group, gender, batch or in any particular country with Covid-19 Vaccine AstraZeneca. In fact, the observed number of these types of events is significantly lower in those vaccinated than what would be expected among the general population."

\section{Disease related clotting}

Commenting on the decisions, Stephen Evans, professor of pharmacoepidemiology at the London School of Hygiene \& Tropical Medicine, said, “The problem with spontaneous reports of suspected adverse reactions to a vaccine [is] the enormous difficulty of distinguishing a causal effect from a coincidence." He highlighted that covid-19 disease was very strongly associated with blood clotting and that there had been hundreds, if not many thousands, of deaths caused by blood clotting as a result of covid-19.

Adam Finn, professor of paediatrics at the University of Bristol, said, “The position with the there is no sign anywhere, including the UK where very large numbers of doses have now been given, that blood clot related illnesses are happening any more frequently than usual.

“That's reassuring, because it means either that the vaccine doesn't cause blood clots at all or, at the very worst, that it's an extremely rare event."

\section{Addendum: We amended this article on 12 March 2021 to add Italy to the list of countries mentioned in paragraph 2 and to include an updated statement from AstraZeneca in paragraphs 7 and 8. Paragraph 8 replaces the original sentence, "The safety of the vaccine has been extensively studied in phase III clinical trials, and peer reviewed data confirms the vaccine has been generally well tolerated."}

This article is made freely available for use in accordance with BMI's website terms and conditions for the duration of the covid-19 pandemic or until otherwise determined by BMJ. You may use, download and print the article for any lawful, non-commercial purpose (including text and data mining) provided that all copyright notices and trade marks are retained.
Oxford-AstraZeneca vaccine at the moment is that 